\title{
Mercury (II) Binding Activity of Vegetable and Fruit Juices: Identifying Potential Detoxifying Juices for the Citizens of Portovelo-Zaruma, Ecuador
}

\author{
Eduardo Jovel ${ }^{1}$, Zyta Abramowski ${ }^{1}$,Elena Pakalnis ${ }^{2}$, Bruce Marshall ${ }^{2 *}$ and Marcello Veiga $^{2}$ \\ ${ }^{1}$ University of British Columbia, Indigenous Health and Natural Products Chemistry Laboratory, Canada \\ ${ }^{2}$ University of British Columbia, Norman B Keevil Institute of Mining Engineering, Canada
}

*Corresponding author: Bruce Marshall, University of British Columbia, Norman B Keevil Institute of Mining Engineering, 6350 Stores Road, V6T 1Z4 Vancouver, BC, Canada

Submission: 海 May 04, 2018; Published:

\begin{abstract}
Artisanal gold mining is known to cause high levels of mercury $(\mathrm{Hg})$ contamination to human populations, due mainly to many miners burning gold amalgams without the use of safety equipment and/or mercury capture systems. In Portovelo-Zaruma, Ecuador, there are more than 10,000 people directly involved in artisanal mining. As $\mathrm{Hg}$ vapour accumulates in the kidneys and brain, it is important to investigate potential agents that may be effective in helping to detoxify contaminated individuals. In this study, selected vegetable and fruit juices were evaluated for their mercury (II) binding capabilities and their potential use as Hg detoxifying agents. Vegetables and fruits were selected based on results from a survey completed in January/2015 on readily available and frequently consumed foods in the mining district of Portovelo. Mercury (II) binding capabilities were measured by a simple spectro photometric method using diphenyl thiocarbazone (dithizone) to determine the amounts of mercury (II) in the juice samples. Juices from the Families Brassicaceae (kale, broccoli, cabbage, cauliflower), Amaryllidaceae (garlic), and Solanaceae (bell peppers) were the most active in binding to mercury (II). Little binding activity was present in other tested juices, including beets, carrots, celery, green apples, tamarillos, and tomatoes. In addition, no correlation was found between reported methionine, cysteine, and selenium content in analysed juices and Hg (II) binding activity. Assessment of bioavailability of methyl mercury ( $\mathrm{Me} \mathrm{Hg}$ ) in tuna using an in vitro digestion model in the presence of vegetable and fruit juices has been initiated to determine the breakdown and binding of mercury in the juices.
\end{abstract}

Keywords: Mercury decontamination; Hg (II) binding activity; Artisanal gold miners; Ecuador

\section{Introduction}

Artisanal gold mining, especially in developing countries, is defined by the use of rudimentary techniques to extract ore and process the gold, which mainly involves amalgamation. The use of mercury in gold processing, especially when involving the whole ore, as opposed to simply amalgamating the concentrates, is highly inefficient, culminating in losses of up to $50 \%$ of the initial mercury introduced $[1,2]$. Although the largest environmental problem in gold mining is the release of mercury and other heavy metals in tailings to fluvial drainages, the most serious health problem is the burning of gold amalgams. Although the use of mercury is prohibited by international accords like the Minamata Convention (Mercury Convention, 2013), artisanal miners in developing countries like Ecuador routinely use open pans to burn the amalgams without any protective safety equipment or mercury capture systems, exposing themselves, family members and the rest of the community to the noxious gases. It has been estimated that inhaled mercury vapour gets absorbed in the lungs at a rate of approximately $80 \%$, where it is rapidly oxidized to the mercuric form $\left(\mathrm{Hg}^{2+}\right)$ in the red blood cells and distributed to all of the tissues and organs, including the brain [3]. The objective of this study was to evaluate selected vegetable and fruit juices for their mercury (II) binding capabilities and their potential use as $\mathrm{Hg}$ detoxifying agents.

\section{Mercury de-toxification}

There are numerous studies, mostly in vitro, some in vivo, supporting evidence of heavy metal detoxifying properties of dietary fibre, natural polymers like algal polysaccharides, pectins, lignins and sulphur containing peptide foods like alliums and Brassicas [4] For instance, mice exposed to methyl mercury and fed wheat bran diets displayed lower concentrations of mercury in the brain and blood and higher excretion, suggesting modifications of organomercurials by gut flora metabolism [5]. Similarly, phytosorbent prepared from black sunflower husks and containing lignin, cellulose and melanin decreased mercury accumulation in the kidneys and muscles of adult rabbits exposed to mercury [6]. The effect of selenium doses on mercury distribution and retention 
in suckling rats was investigated by [7]. Even though there was a decrease of mercury in the organs, higher concentrations of $\mathrm{Hg}$ (II) were found in the plasma and urine than in erythrocytes. This was observed by increasing the dose of selenium, suggesting a redistribution of mercury from the plasma to erythrocytes when the selenium and mercury ratio exceeded equimolar.

Although human studies investigating the impacts of food and nutrition supplements on reducing mercury toxicity in exposed individuals remain limited, there are a few of worthwhile note. For example, a large-scale study evaluating exposure by dentists to low levels of mercury confirmed the inhibition of mercury absorption by dietary ethanol [8]. Residents of a former mercury mining area in Wanshan, China, with mild mercury exposure as indicated by blood analysis, showed benefits of a selenium-enriched diet [9]. Subjects of this three-month controlled study took selenium yeast product and had a higher urinary mercury excretion than the placebo group. Five case studies investigated by Eliaz et al. [10] who exposed human subjects to modified citrus pectin (PectoSol-C) or alginate combinations, showed an average reduction of $74 \%$ in lead and mercury burden. These studies were funded by EcoNugenicsInc, the producer and patent holder for the product [10].

The combination of PectoSol-C and alginates was also shown to significantly decrease the urinary excretion of arsenic, lead, and cadmium in healthy individuals [11]. In children aged 5 to 12 , a substantial decrease in blood lead levels was found, as well as an increase in lead excreted through their urine. These children had blood serum levels greater than $20-\mu \mathrm{g} / \mathrm{ml}$ after oral administration of PectSol-C, which was reported by [12].

Animal studies are expensive and controlled (double-blinded) human studies are very difficult to design and implement. In terms of mercury, blood and urine tests are only relevant if measured within adequate intervals for each mercury species peak before tissue equilibration [13]. Furthermore, mercury absorption, distribution, and re-distribution in the human body are impossible to measure accurately.

Some studies point to the modification of mercury toxicity by nutrition [14]. For example, not all methyl mercury consumed from fish is bio available. Bioavailability is defined as the amount of orally introduced contaminant in food which reaches systemic circulation $[15,16]$. Oral bioavailability of a compound consists of: the release of the compound from the food matrix into the digestive juice in the gastrointestinal tract (bio accessibility), transport through the intestinal epithelium (intestinal transport) and the degradation of the compound in the liver and intestine (metabolism) [16].

Several in vitro digestive models for food applications were developed and reviewed by Hur et al. (2011). There are twostep digestive models (stomach, duodenum), three-step (mouth, stomach, duodenum), starve $[15,16]$ conditions to evaluate the bio accessibility of mercury. Furthermore, in vitro digestion models can be combined with the intestinal Caco-2 cells transport to determine bioavailability [16].
In vitro digestion models have been used to estimate the bio accessibility of heavy metals in rice and to establish the dependence of an ingestion matrix like soil on lead bio accessibility $[15,16]$ demonstrated almost $100 \%$ bio accessibility of mycotoxins: aflatoxin B1 from peanut slurry and ochratoxin A from buckwheat and its modulation by additives like charcoal, cholestyramine, and aluminosilicol. Although chlorophyllin did not reduce bio accessibility, the intestinal transport of aflatoxin B1 was affected, which was corroborated with other animal and human studies [17] found low $(<20 \%) \mathrm{Hg}$ bio accessibility in fish using in vitro stomach and intestinal digestion systems. However, from the same study, selenium (Se) was highly bio accessible, with results of $50 \%$ and $83 \%$ respectively. Furthermore, it was determined from the $\mathrm{Se} / \mathrm{Hg}$ ratios that selenium influenced $\mathrm{Hg}$ bio accessibility. Spiegel et al. [18] showed the effect of phyto chemical-rich foods on reducing mercury bio accessibility in fish. While green and black tea extracts, soy protein and wheat bran all reduced mercury bio accessibility significantly in the dose-dependent manner, oat bran and psyllium were less effective and grapefruit juice was not active. Caco-2 transport as a predictor of intestinal transport was not used in this study.

\section{Health effects of mercury vapour inhalation}

Due to the proliferation of gold shops in Portovelo-Zaruma, Ecuador that burn amalgams without the use of mercury capture systems, resident populations in the area are at risk of mercury contamination, especially children, pregnant mothers and women of childbearing age. This is a common occurrence in artisanal gold mining areas around the world, where mercury vapours are emitted due to Hg use in small ball mills to amalgamate the gold and also via the burning of amalgams to obtain approximately 99\% pure gold (doré). Although inhalation of $\mathrm{Hg}$ vapour is more significant for miners and gold shop workers who are directly involved in handling metallic $\mathrm{Hg}$, it can also affect surrounding communities indirectly [19]. The recommended maximum health-based exposure limit of metallic $\mathrm{Hg}$ for workers (8-h/day) is $25,000 \mathrm{ng} / \mathrm{m}^{3}$. The normal atmospheric levels of $\mathrm{Hg}$ in rural areas are about $2-4 \mathrm{ng} / \mathrm{m}^{3}$, and in urban areas about 10 to $20 \mathrm{ng} / \mathrm{m}^{3}$ [20].

The biological half-life of $\mathrm{Hg}$ in the blood when absorbed as vapour is approximately 2-4 days, whereby $90 \%$ is excreted through urine and feces. The remaining $10 \%$ has a half-time of 15-30 days $[21,22]$. With exposure to considerable levels of $\mathrm{Hg}$ vapour over moderate duration, kidneys are the most affected organs, while the brain is the dominant receptor in long-term exposure of moderate levels [23]. Several studies have shown that mild subclinical signs of central nervous system toxicity can be observed among people who have been exposed occupationally to elemental mercury at a concentration of $20 \mu \mathrm{g} / \mathrm{m}^{3}\left(20,0001000 \mathrm{ng} / \mathrm{m}^{3}\right)$ or above for as little as a year $[24,25]$. The LOAEL (Lowest Observed Adverse Effect Level) for mercury vapour is between $15-30 \mu \mathrm{g} / \mathrm{m}^{3}$ [26]. Applying an uncertainty factor of 20 (10 for uncertainty due to variable sensitivities in higher risk populations and, on the basis of doseresponse information, a factor of 2 to extrapolate from a LOAEL to a likely No Observed Adverse Effect Level (NOAEL), a guideline for 
maximum public exposure of inorganic mercury vapour of $1 \mu \mathrm{g} / \mathrm{m}^{3}$ or $1000 \mathrm{ng} / \mathrm{m}^{3}$ as an annual average has been established [27].

Short-term exposure to high mercury levels causes clinical symptoms that mainly involve the respiratory tract. Clinical symptoms typically associated with high, short-term exposure to mercury vapour (1000 to over $44,000 \mu \mathrm{g} / \mathrm{m}^{3}$ ), such as when miners burn amalgams in open pans, include chest pains, dyspnoea, cough, haemoptysis, impairment of pulmonary function, interstitial pneumonitis, and death $[27,28]$ determined that even a few hours of exposure to high $\mathrm{Hg}$ levels of 1,000 to $2,000 \mu \mathrm{g} / \mathrm{m}^{3}$ may cause acute chemical bronchitis and pneumonitis [29] in a study of $\mathrm{Hg}$ vapour intoxication of gold mining workers and surrounding communities in El Callao, Venezuela, found neurological signs in miners, women and children that included ataxia, trembling of the hands and eyes, incapability of performing the finger-nose test, dysdiadochokinesia, patellar and hyper-reflexia, and patellar and cubital hypo-reflexia. When correlating the neuropsychological tests with levels of $\mathrm{Hg}$ in urine, it was observed that individuals with concentrations above $50 \mu \mathrm{g} \mathrm{Hg} / \mathrm{g}$ creatinine showed difficulties in completing the WMS-Memory Test. (Table $1 \& 2$ ) in the appendix list the potential symptoms caused by exposure to mercury vapour, as followed by several negative outcomes of high exposure to metallic mercury vapour in regions within a proximal distance to gold shop/gold mines [1]. Investigating mercury vapour emissions in the gold processing region of El Pache in Portovelo, measured $\mathrm{Hg}$ concentrations of $2356.7 \pm 1807.6 \mathrm{ng} / \mathrm{m}^{3}$ and $3699.5 \pm 1225.3 \mathrm{ng} /$ $\mathrm{m}^{3}$ in the rainy and dry seasons, respectively. Although lower atmospheric mercury levels were detected in the urban central area of Portovelo, with $\mathrm{Hg}$ concentrations of $214.6 \pm 43.7 \mathrm{ng} / \mathrm{m}^{3}$ in the wet season and $574.2 \pm 72.8 \mathrm{ng} / \mathrm{m}^{3}$ in the dry season, they still exceeded the minimum public exposure risk level of 200ng/ $\mathrm{m}^{3}$, determined by the Agency for Toxic Substances and Disease Registry(a federal public health agency within the United States Department of Health and Human Services).In comparison, a 2014 monitoring study of mercury emissions [30] in El Pache found concentrations that ranged from 200 to more than $50,000 \mathrm{ng} / \mathrm{m}^{3}$. Furthermore, average $\mathrm{Hg}$ concentrations above $200,000 \mathrm{ng} / \mathrm{m}^{3}$ were reached when visiting processing centers, with highs of over $2,000,000 \mathrm{ng} / \mathrm{m}^{3}$ registered during the burning of amalgams from over $15 \mathrm{~m}$ away, adjacent to dormitories used by miners. As part of the same study, atmospheric mercury monitoring in Zaruma in July/2015 outside of a gold shop showed concentrations above $1,000,000 \mathrm{ng} / \mathrm{m}^{3}$, with highs $>2,000,000 \mathrm{ng} / \mathrm{m}^{3}$ registered inside the shop immediately after the burning of a gold amalgam. Although the shop had a chimney for expelling the fumes, there was no use of safety equipment nor any kind of mercury capture system. It should also be noted that spikes exceeding $500,000 \mathrm{ng} / \mathrm{m}^{3}$ were also attributed to miners simply entering the shop wearing clothing contaminated with mercury fumes [31]. Also measured the amount of mercury in exhaled air from miners in Portovelo before and after the burning of amalgams, which varied from $170-1352 \mathrm{ng} / \mathrm{m}^{3}$ prior to burning to $2007-3389 \mathrm{ng} / \mathrm{m}^{3}$ afterwards. Considering that $1000 \mathrm{ng} / \mathrm{m}^{3}$ has been established as the guideline for maximum public exposure of inorganic mercury vapour [26] these results show significant levels of occupational mercury contamination. In October/2015, the Instituto Nacional de Salud, in conjunction with the Universidad de los Andes in Colombia, conducted a study to evaluate the health impacts of exposure to mercury for artisanal gold miners and their families in 11 municipalities from the La Mojana region of Colombia [32]. The study determined Hg concentrations in blood, urine and hair for different age groups at risk of either occupational or environmental exposure to mercury. The results from the Colombian National Health Institute study showed that the highest mercury levels were found in the urine, with maximum concentrations of $85 \mu \mathrm{g} / \mathrm{L}$, which is over 3 times the occupational exposure limit of $25 \mu \mathrm{g} / \mathrm{L}$ [33]. Considering that many vulnerable populations were also included in this study (children, pregnant women and women of child bearing age), it appears that the risk of mercurial toxicity due to inhalation of mercury vapour is very high.

Table 1: The methionine, cysteine and selenium content in selected fruits, vegetables, nuts and cow milk (Nutrition Data, 2017).

\begin{tabular}{|c|c|c|c|c|}
\hline Source & $\begin{array}{l}\text { Selenium } \\
\mu \mathrm{g} / 100 \mathrm{~g}\end{array}$ & $\begin{array}{l}\text { Methionine } \\
\text { (mg/100g) }\end{array}$ & $\begin{array}{l}\text { Cysteine } \\
\text { (mg/100g) }\end{array}$ & $\begin{array}{c}\text { Alanine } \\
(\mathrm{mg} / \mathbf{1 0 0 g})\end{array}$ \\
\hline Almond nut milk & 2.5 & 151 & 189 & 1027 \\
\hline Apple & $\sim$ & 1 & 1 & 11 \\
\hline Beets & 0.7 & 18 & 0.7 & 60 \\
\hline Brazil nut milk & $1,917.00$ & $1,008.00$ & 367 & 577 \\
\hline Broccoli & 2.5 & 38 & 28 & 104 \\
\hline Green Cabbage & 0.3 & 12 & 11 & 42 \\
\hline Carrots & 0.1 & $\sim$ & $\sim$ & $\sim$ \\
\hline Cauliflower & 0.6 & 28 & 23 & 104 \\
\hline Celery & 0.4 & 5 & 4 & 23 \\
\hline Cilantro & 0.9 & $\sim$ & $\sim$ & $\sim$ \\
\hline Cow milk (2\%) & 2.5 & 83 & 107 & 111 \\
\hline Garlic & 14.2 & 76 & 14.2 & 132 \\
\hline
\end{tabular}




\begin{tabular}{|c|c|c|c|c|}
\hline Kale & 0.9 & 32 & 44 & $\sim$ \\
\hline Lemon & $\sim$ & $\sim$ & 0.7 & 766 \\
\hline Orange & 0.7 & 27 & 0.1 & 26 \\
\hline Red Pepper & 0.1 & 6 & 17.9 & 53.6 \\
\hline Green Pepper & 0 & 10.4 & 1 & 142 \\
\hline Spinach & 1 & 53 & 0 & 27 \\
\hline Tomato & 0 & 6 & & 70 \\
\hline
\end{tabular}

Table 2: The binding capacity of vegetables $(>75 \%)$ at $50 \%$ juice concentration.

\begin{tabular}{|c|c|}
\hline Juice at $\mathbf{5 0} \%$ Concentration & \% of Hg (II) Binding \\
\hline Red Pepper & 99.83 \\
\hline Kale & 98.75 \\
\hline Brocolli & $98.67 \mathrm{C}$ \\
\hline Garlic & 93.53 \\
\hline Green Pepper & 91.65 \\
\hline Cauliflower & 90.16 \\
\hline Spinach & 76.31 \\
\hline
\end{tabular}

Under circumstances of high exposure to mercury vapour (eg occupational settings), blood inorganic mercury has been found to be elevated and correlates closely with urinary mercury [34]. Urinary mercury is the preferred biomarker indicating exposure to inorganic mercury and over time increases in response to exposure to low levels of mercury vapour[34]. Based on likely half-lives of 40-90 days, urinary mercury is an integrated marker of exposure over previous months [35].

Considering the mercury exposure risks for artisanal miners and their families in Portovelo, Ecuador, where gold processing using mercury and gold shops burning gold amalgams can be found in dense concentration, it is important to find ways to help detoxify contaminated individuals. Therefore, the main objective of this study is to identify which fruits and vegetables readily available in Portovelo have high mercury (II) binding capacity potential, in order to develop palatable juice combinations for locals to drink on a regular basis. In future, studies could be implemented to analyze mercury (II) levels in blood and urine to verify whether the juices are effective as $\mathrm{Hg}$ reduction agents.

\section{Material and Methods}

\section{Determination of mercury (ii) levels in the samples}

The spectrophotometric method [36] was used with slight modifications to determine mercury (II) concentrations in the samples. Dithiazone, in slightly acidic conditions, reacts with mercury (II) and produces an orange chelate $(488 \mathrm{~nm}$ absorption max). $10 \mathrm{mg} / \mathrm{ml}$ of mercury (II) standard solution was prepared in a $100 \mathrm{ml}$ volumetric flask by dissolving $1.355 \mathrm{~g}$ of mercuric chloride in distilled water. The stock solution was stored at $40{ }^{\circ} \mathrm{C}$ and used for all of the dilutions. A nine-point standard curve with concentrations ranging from 1 to $100 \mu \mathrm{g} / \mathrm{mL}$ of mercury (II) was constructed, whereby $0.5 \mathrm{ml}$ of samples containing mercury (II) was combined with $0.5 \mathrm{ml}$ of dithiazone $(37.2 \mathrm{mg}$ of dithiazone in $100 \mathrm{ml}$ of 1,4 dioxane). Chelate was acidified with $0.05 \mathrm{~mL}$ of $4.5 \mathrm{M}$ sulphuric acid, solubilized with $2.5 \mathrm{~mL}$ of 1,4 dioxane and diluted with $1.45 \mathrm{~mL}$ of distilled water to reach a total volume of $5.0 \mathrm{ml}$. A blank reagent with no mercury was prepared at the same time with $0.5 \mathrm{~mL}$ of distilled water. Samples were incubated at room temperature (RT) for 24 hours and absorption at $488 \mathrm{~nm}$ was determined against the blank using a Pharmacia Biotech Ultrospec 1000 (Cambridge, England) spectrophotometer with disposable acrylic cuvettes (BRAND GMBH+CO KG, Germany). The mercury concentrations of unknown samples were determined from the standard calibration curve (Figure 1).

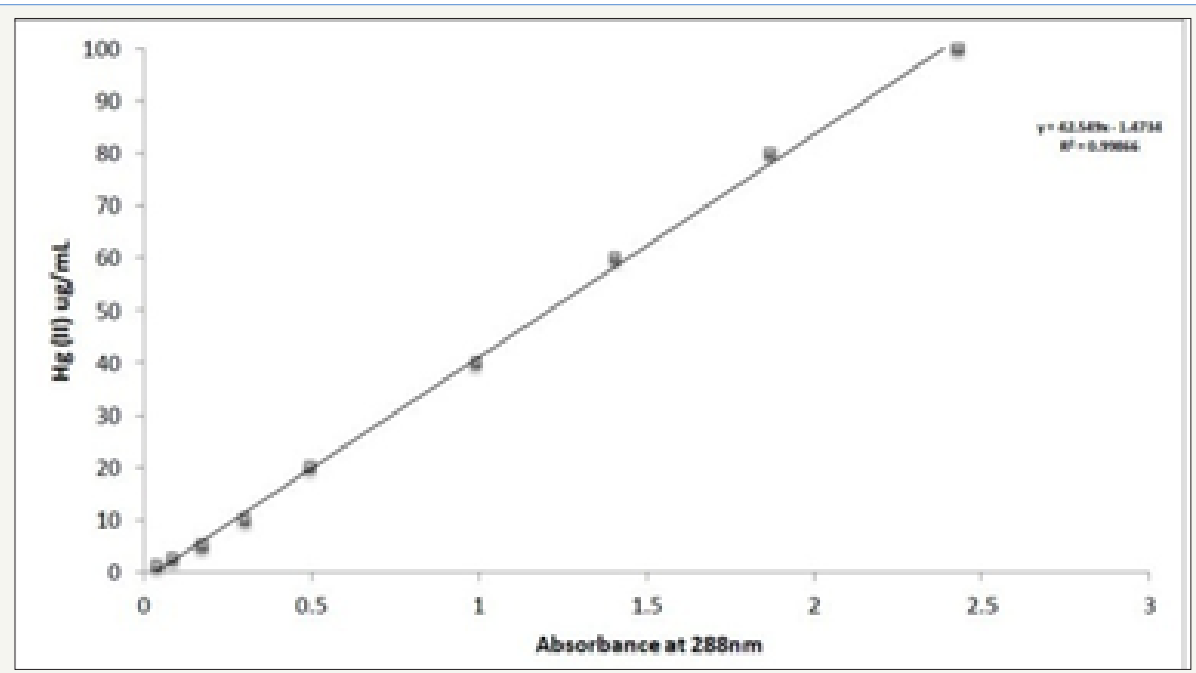

Figure 1: Standard calibration curve for Hg (II)-dithiazone complex. 


\section{Method validation with known chelators and adsorbents}

The method was validated with known chelators like pharmaceutical Dimercaptosuccinic acid (DMSA), pharmaceutical and endogenous thiol, N-acetylcysteine (NAC), natural product, PectoSol-Modified Citrus Pectin (MCP) and charcoal (Biochar). Freshly prepared DMSA and NAC solutions were mixed in distilled water with $\mathrm{Hg}$ (II) dilutions in different ratios and incubated for 1 hour at RT with shaking at approximately 130 revolutions per minute. MCP (PectoSol-C) and charcoal were mixed with Hg (II) dilutions at different ratios and incubated for 1 hour at RT with shaking at approximately 130 revolutions per minute. The free $\mathrm{Hg}$ (II) in the samples was determined by the spectrophotometric method of [36] after 20 minutes of centrifugation at $16 \mathrm{~K} x \mathrm{~g}$ at RT. Charcoal treated samples were additionally filtered through $0.2 \mu \mathrm{m}$ Nalgene filters to remove the remaining fine particles.

\section{Determination of mercury (ii) binding capacity of}

\section{vegetable and fruit juices and nut milk}

Vegetables and fruits were washed, blotted with paper towels, weighed and juiced with a Breville (Fountain Elite) juicer. Fresh juices were used immediately and remaining material was frozen right away in $50 \mathrm{~mL}$ conical tubes at $-20{ }^{\circ} \mathrm{C}$. Red bell peppers and cabbage were also freeze-dried using an Edwards MODULY04K freeze drier to compare the activity of fresh versus freeze-dried samples. Juices were diluted with distilled water to obtain 90, 75, 50,25 and 10 percent of juice in the tested samples. Mercury (II) was added to $90,75,50,25$ and 10 percent of juice in the tested samples for the final concentration $1 \mathrm{mg} / \mathrm{mL}$. All test samples were made in duplicate in the scintillation vials. Simultaneously, $90,75,50,25$ and 10 percent of tested juice without mercury (II) were prepared to establish individual Absorbance (A) at $488 \mathrm{~nm}$. The control, $100 \% \mathrm{Hg}$ (II), consisted of 0.1 or $1 \mathrm{mg} / \mathrm{mL}$ of $\mathrm{Hg}$ (II) in water. Juices with or without mercury (II) and controls, as well as controls, were incubated for 1 or 24 hours at RT with shaking at approximately 130 revolutions per minute. Liquids were transferred with transfer pipettes to $1.6 \mathrm{~mL}$ Eppendorf tubes and then centrifuged for 20 minutes at $16 \mathrm{~K} \mathrm{x} \mathrm{g}$ at RT (Sorvall Legend Micro 17R, Thermo Electron LED Gmbh, Osterode, Germany). Free $\mathrm{Hg}$ (II) was determined in the clear liquids by the slightly modified method of [36], as described above.

The mean concentrations of the controls were calculated from the standard calibration curve and used to represent $100 \%$ of available free $\mathrm{Hg}$ (II). The mean $\mathrm{Hg}$ concentrations of different strength juices were subtracted from the mean $\mathrm{Hg}$ concentrations of tested juices exposed to $\mathrm{Hg}$ (II), then divided by the mean $\mathrm{Hg}$ control values and expressed as a percentage to determine the change in free $\mathrm{Hg}$ (II) caused by each treatment.

\section{Determination of mercury (ii) binding capacity of nut} and cow milk

Brazil nuts and almonds were mixed with water at the ratio 1:2 and blended in a Warren blender at high speed. The milk was then separated from solids by squeezing through several layers of cheesecloth. Brazil nut, almond and cow milk were evaluated for $\mathrm{Hg}$ (II) binding activity as described above.

\section{Results and Discussion}

Determination of mercury (ii) concentrations in the

\section{samples}

Hg (II) concentrations in unknown samples were determined from the standard calibration curves. Figure 1 shows a typical standard calibration curve. The source (quality) of 1, 4-Dioxane likely influenced the results, probably due to impurities.

\section{Method validation with known chelators and adsorbents}

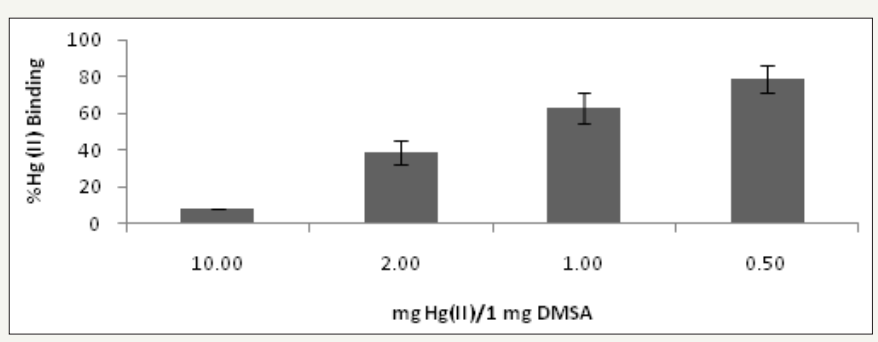

(2a)

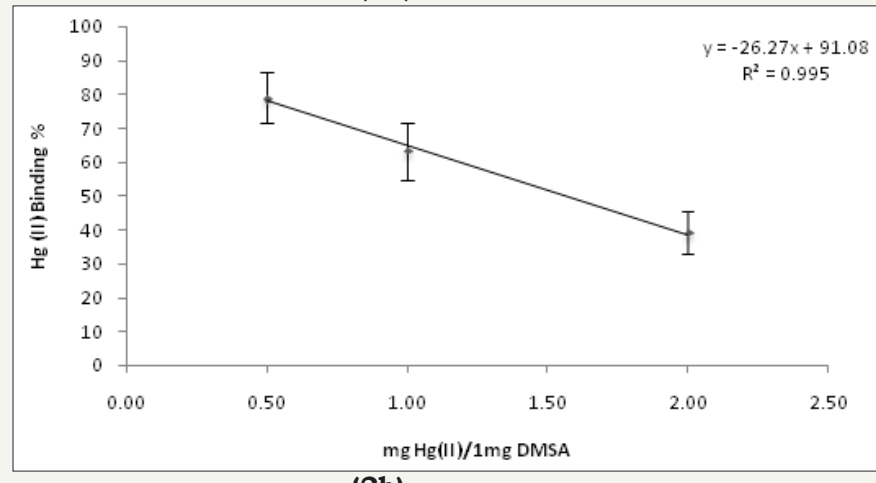

(2b)

Figure $\mathbf{2 a} \boldsymbol{\mathbf { s }} \mathbf{2} \mathbf{b}$ : The $\mathrm{Hg}$ (II) binding activity of DMSA. 


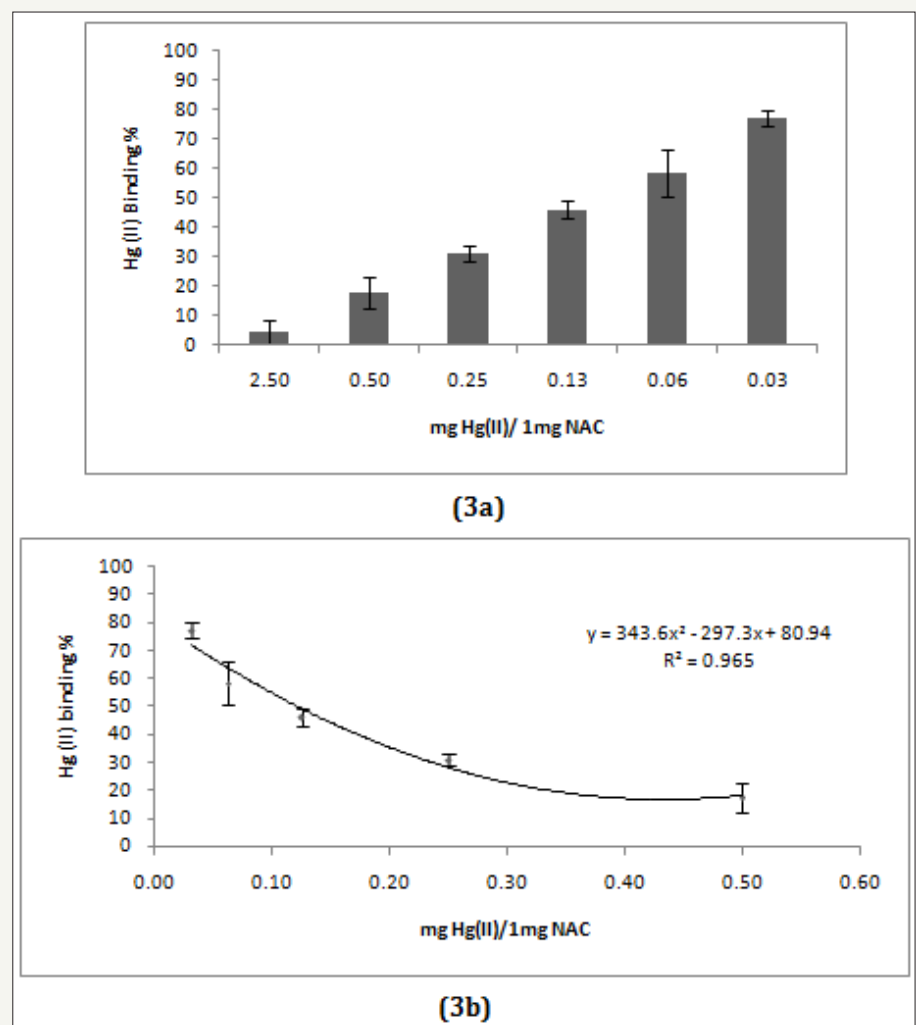

Figure $\mathbf{3 a} \mathbf{8} \mathbf{3} \mathbf{b}$ : The Hg (II) binding activity of NACa.

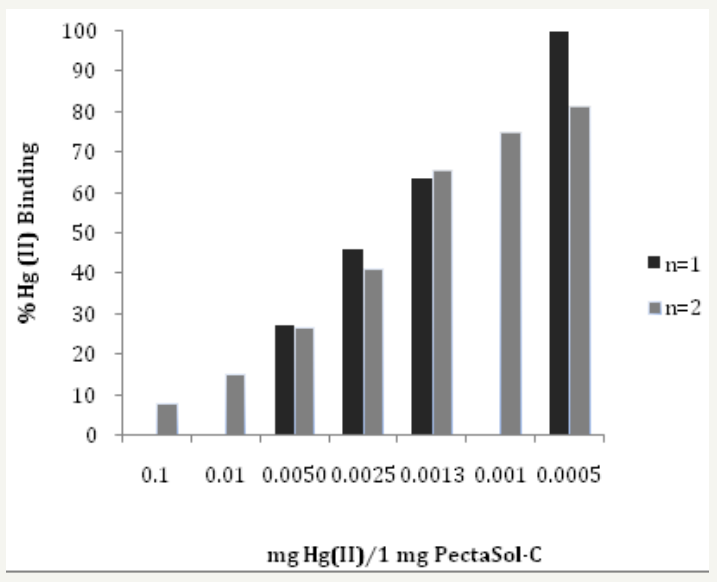

(4a)

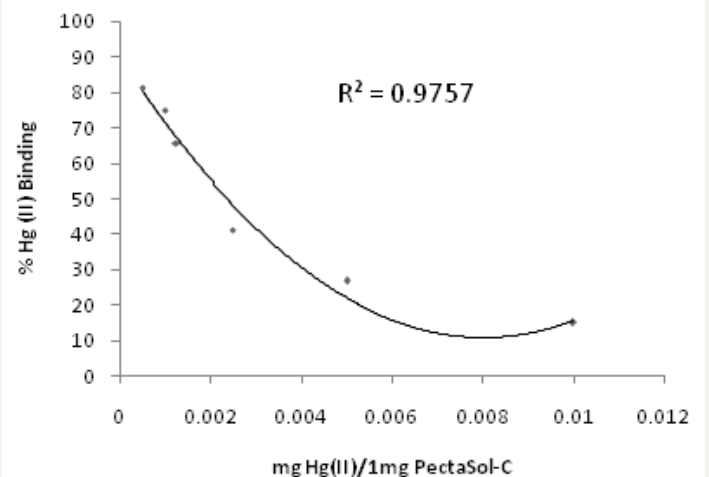

(4b)

Figure 4a $\mathbf{8} \mathbf{4} \mathbf{b}$ : The Hg (II) binding activity of NACa. 


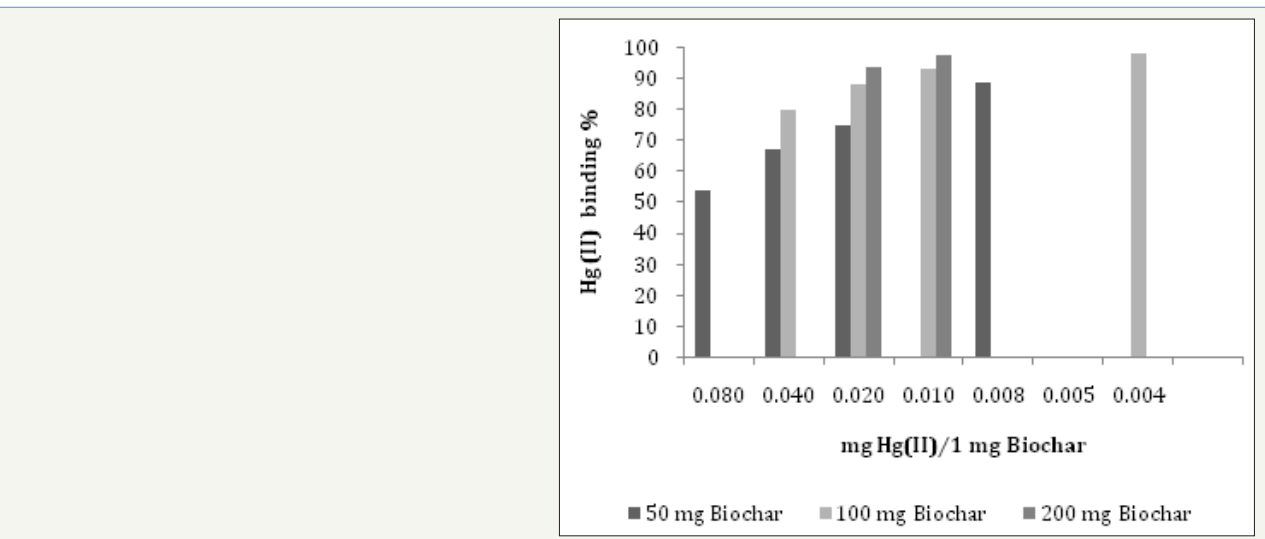

Figures 5: The Hg (II) binding activity of charcoal (Biochar).

Two pharmaceutical chelators (DMSA and NAC), modified citrus pectin (MCP, PectoSol-C) and adsorbent (charcoal-Biochar) were selected for method validation. (Figure $2 a, 2 b$ \& $3 a, 3 b$ ) show the effectiveness of DMSA and NAC in removing Hg (II) cations. As expected,dithiol DMSA was more active than thiol NAC. There have been a large number of studies supporting the usage of pectin for heavy metal detoxification [10-12]. 1mg of PectoSol (Figure 4a \& 4b) removed approximately $50 \%$ of $2 \mu \mathrm{g} \mathrm{Hg}$ (II) from the solution. In comparison, Bio char (Figure 5) was more potent at lower concentrations.

\section{Determination of mercury (ii) binding capacity of vegetable and fruit juices}

Fresh juices were incubated with 0.1 or $1 \mathrm{mg} \mathrm{Hg}$ (II)/mL for 1 hour or 24 hours at RT prior to determining their capacity in removing $\mathrm{Hg}$ from solution. (Figure 6) shows that 1 hour of incubation is sufficient to reveal the $\mathrm{Hg}$ binding activity of juices, which is closer to the time food resides in the stomach. Furthermore, this time duration helps to avoid the possibility of bacterial and fungal contamination. $1 \mathrm{mg} \mathrm{Hg}$ (II)/mL was selected for the screening assay, as the results at this concentration gave a better dose response in comparison to $0.1 \mathrm{mg} \mathrm{Hg}$ (II)/mL (Figure 7). At $0.1 \mathrm{mg} \mathrm{Hg}$ (II) $/ \mathrm{mL}$, samples were used undiluted and the content likely interfered with colorimetric $\mathrm{Hg}$ detection. Cabbage juice was used to test for reproducibility between juicing and comparisons between fresh versus frozen juice, centrifuged or filtered juice (Figure 8). Illustrates good reproducibility between two different juicing of cabbage, with no differences found between frozen or centrifuged juice. Cabbage juice lost at least 50\% $\mathrm{Hg}$ binding activity upon $0.2 \mu \mathrm{m}$ filtration, which suggests adsorption to juice particles as the possible action mechanism. The highest Hg (II) binding activity was observed in juices extracted from Brassicaceae (kale, broccoli, cauliflower and cabbage), Amaryllidaceae (garlic), Capsicum (red and green peppers) and Amaranthaceae (spinach) (Figure 9-11). Surprisingly, apple, beet, carrot, celery, mango, tamarillo and tomato juices demonstrated moderate or no activity while banana, cilantro, lemon, and orange juices displayed good activity (Figure 11).

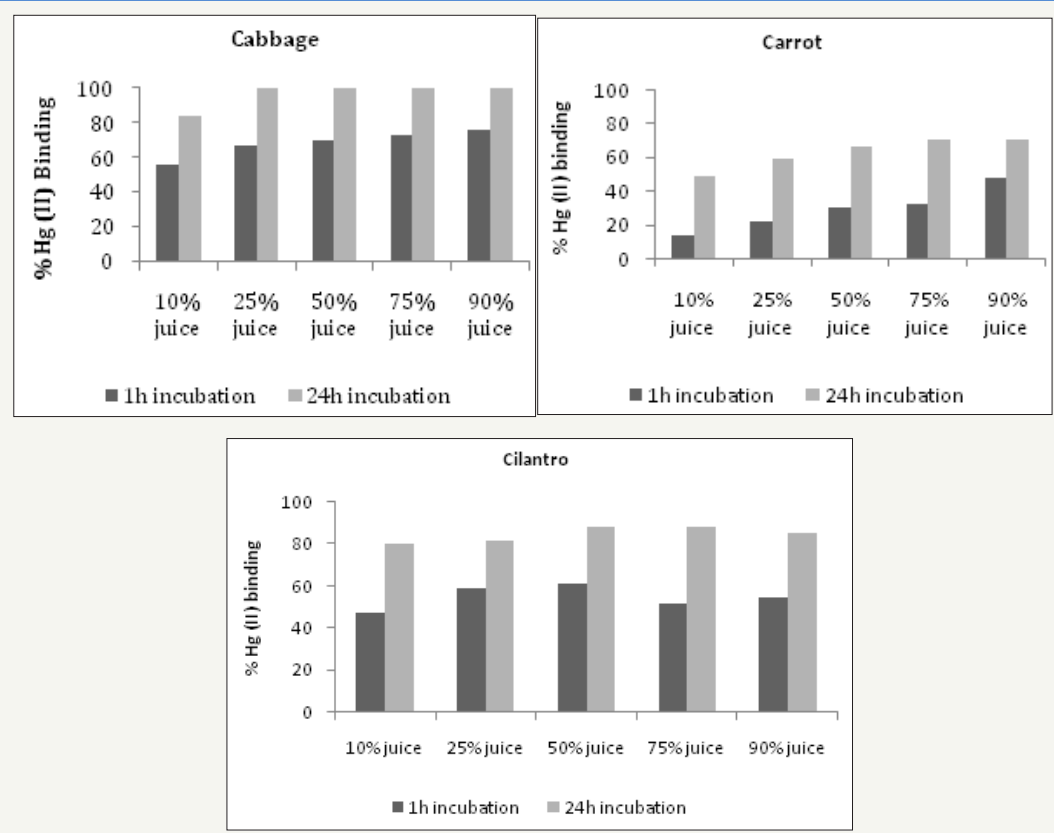

Figure 6: The mercury (II) binding activity of cabbage, carrot, and cilantro juices in relation to incubation time. All juices were tested using a mercury concentration of $0.1 \mathrm{mg} \mathrm{Hg}$ (II) $/ \mathrm{mL}$. 


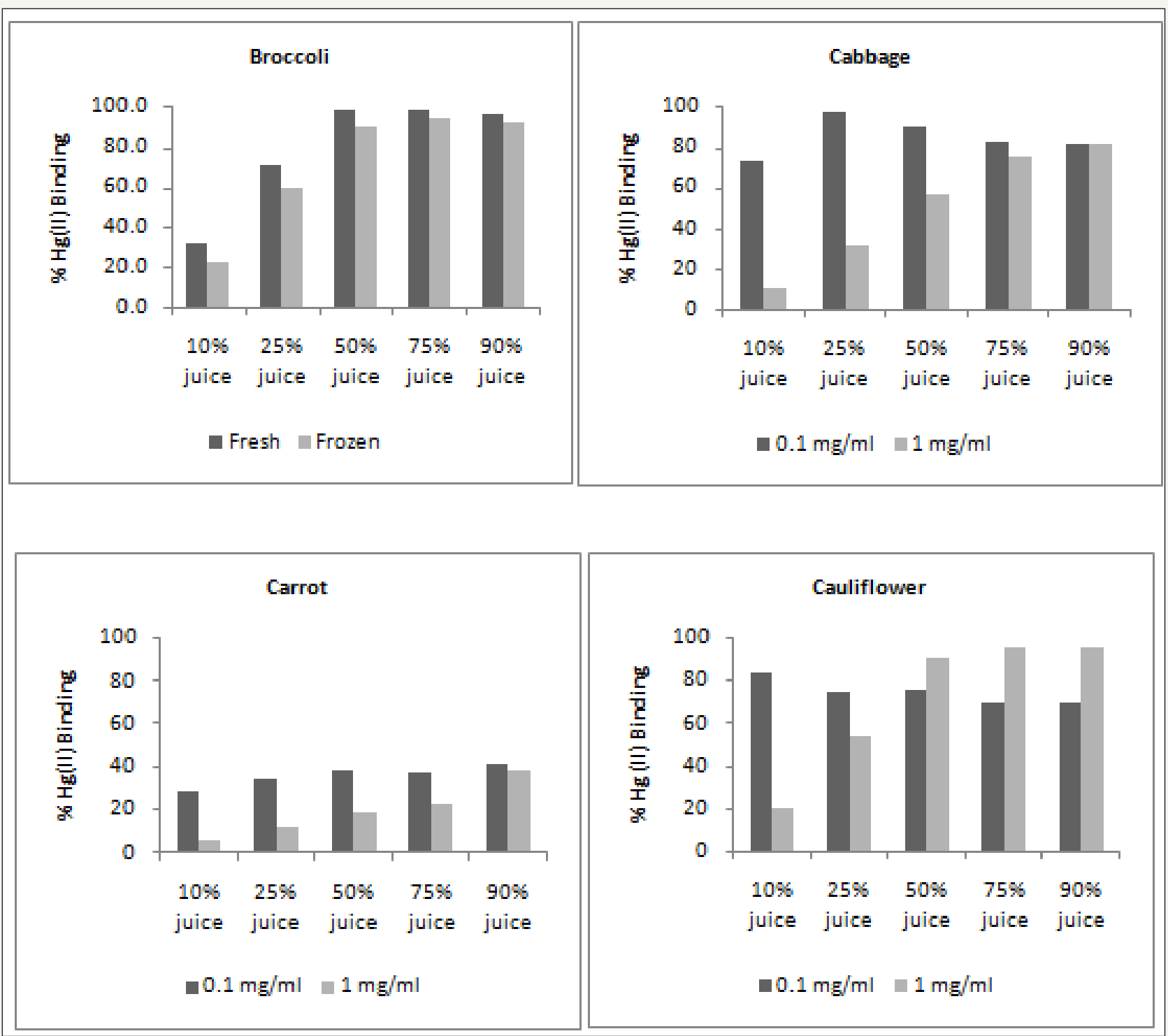

Figure 7: The binding activity of mercury (II) of broccoli, cabbage, carrot, and cauliflower in relation to mercury concentrations $(0.1$ or $1 \mathrm{mg} / \mathrm{mL})$.

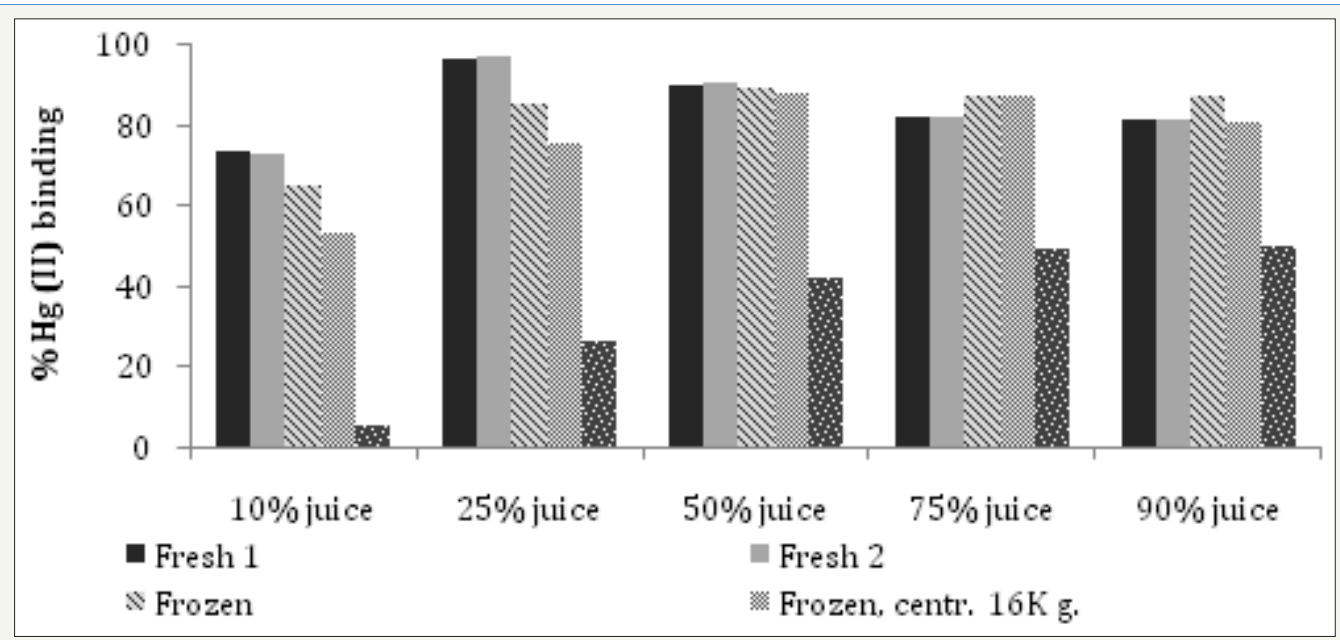

Figures 8: Comparison of the $\mathrm{Hg}$ (II) binding activity of cabbage juice either fresh, previously frozen, centrifuged at 16K x g and supernatant tested or filtered at $0.2 \mathrm{~m}$. All samples were tested using a mercury concentration of $0.1 \mathrm{mg} \mathrm{Hg}$ (II)/mL. 

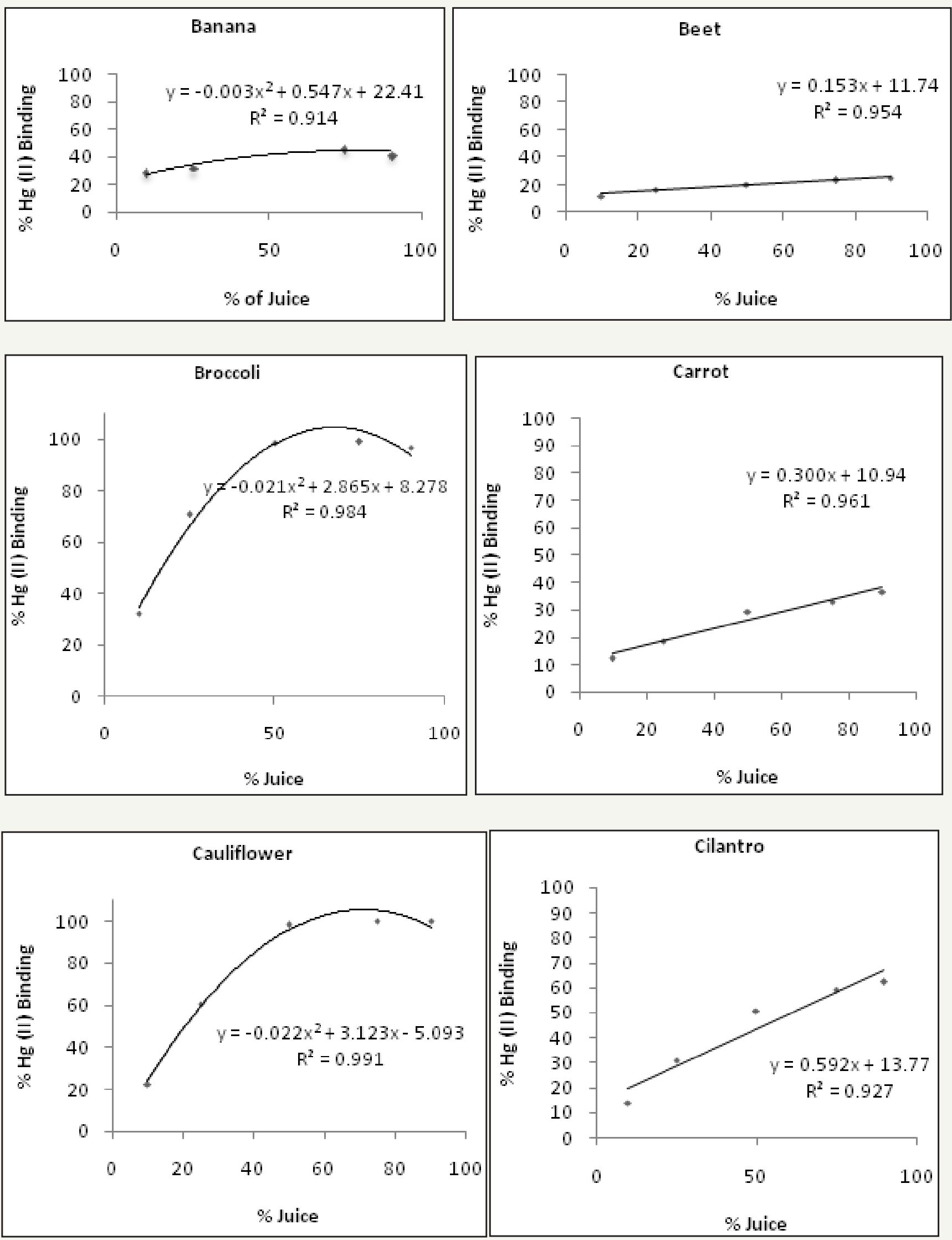

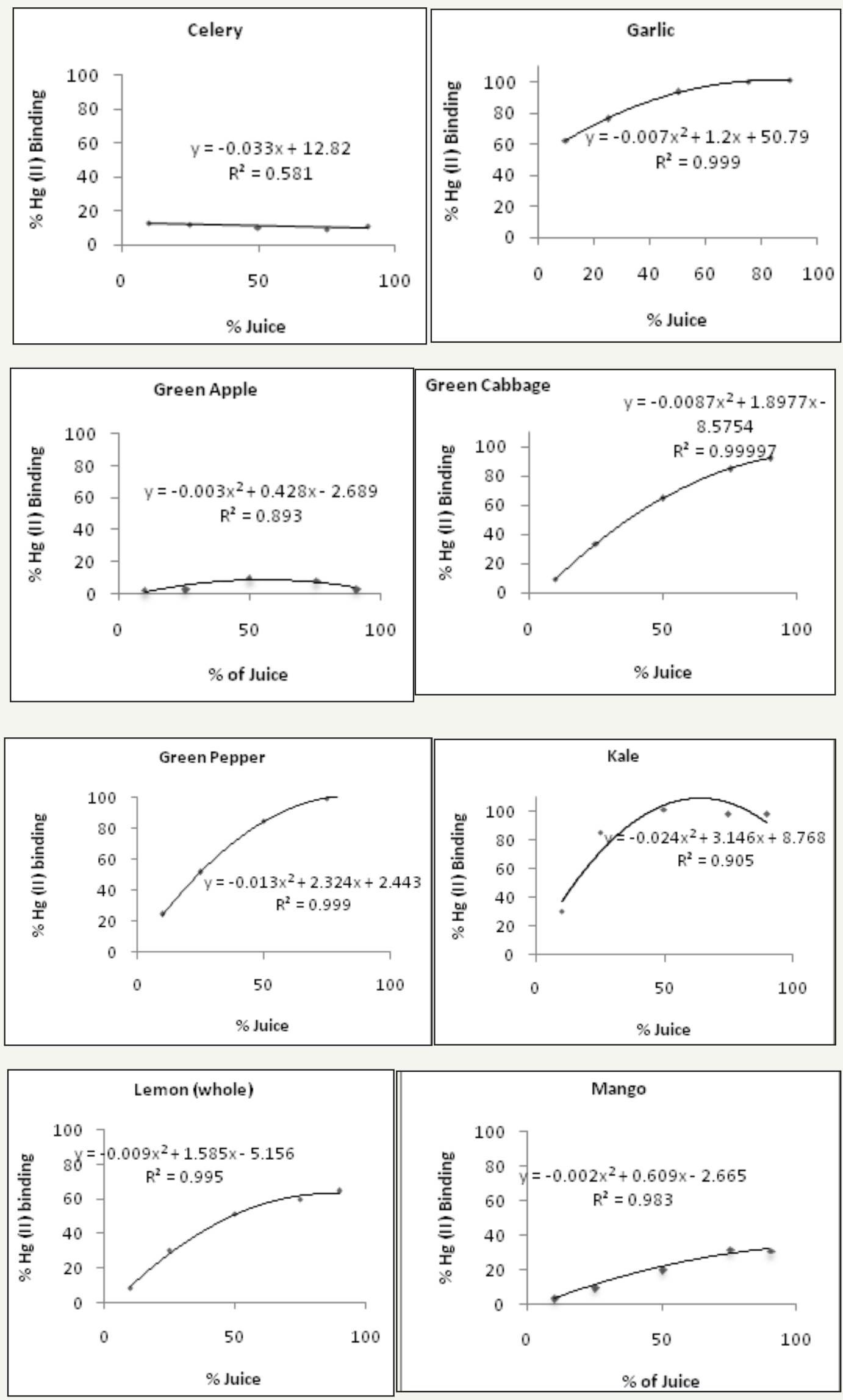

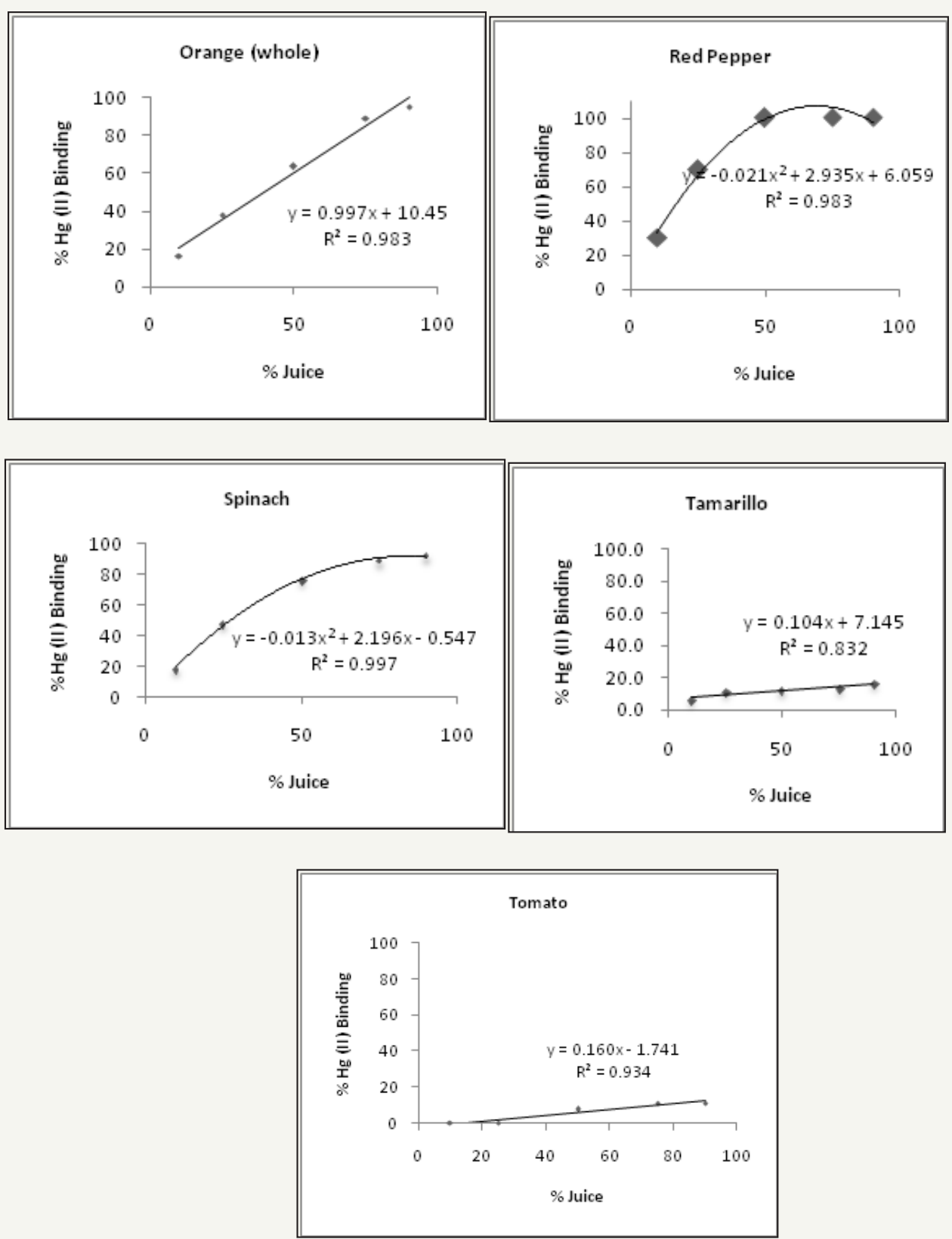

Figure 9: The mercury (II) binding activity of selected vegetable and fruit juices. All juices were tested using a mercury concentration of $0.1 \mathrm{mg} \mathrm{Hg}(\mathrm{II}) / \mathrm{mL}$.

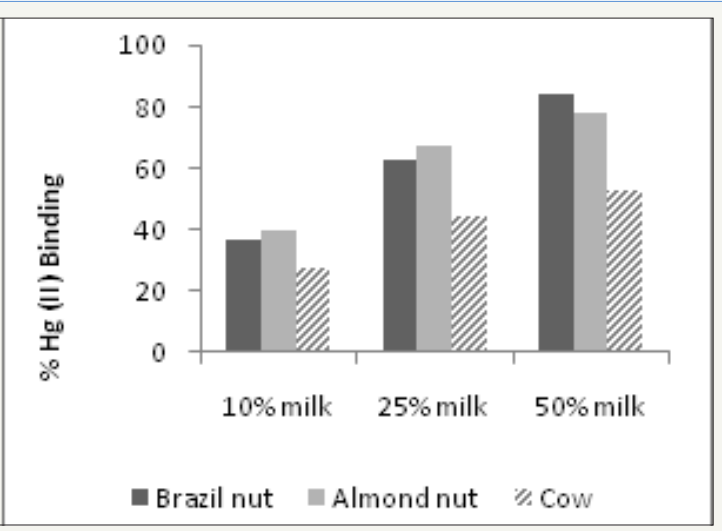

Figures 10: The mercury (II) binding activity of Brazil, almond and cow milk. All milk samples were tested using a mercury concentration of $1 \mathrm{mg} \mathrm{Hg}(\mathrm{II}) / \mathrm{mL}$. 

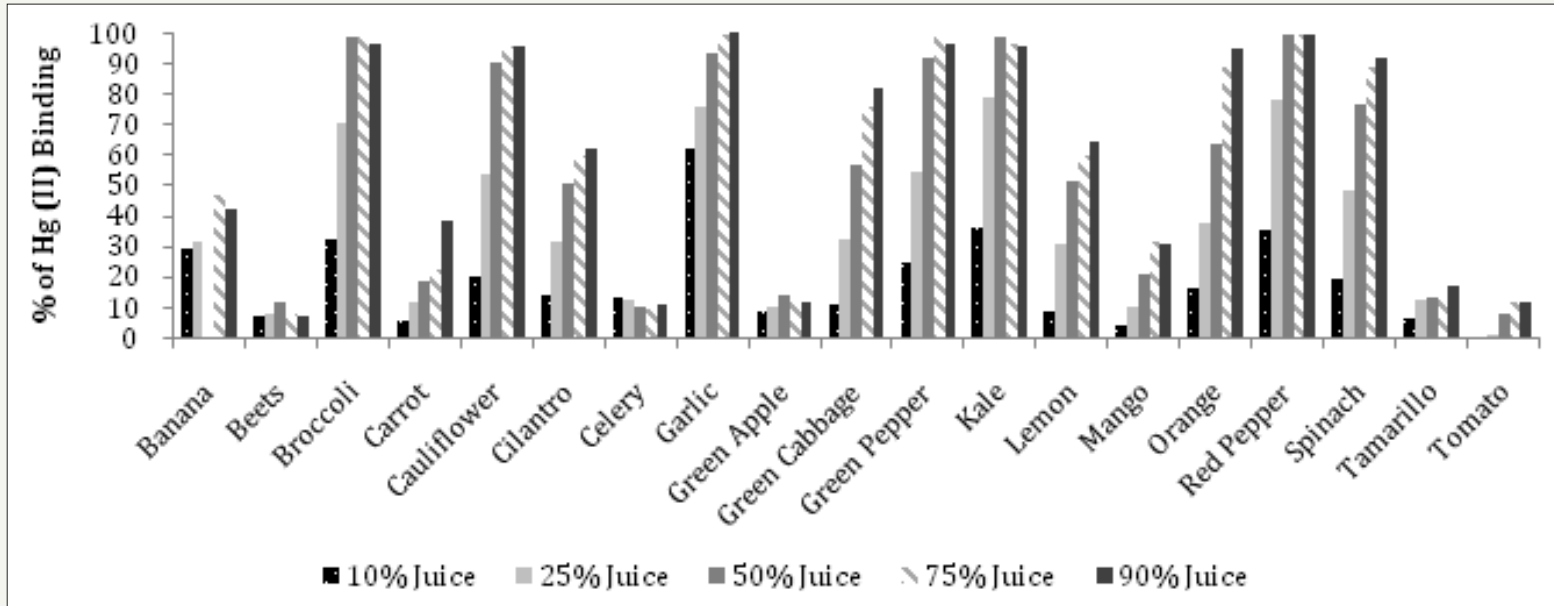

Figures 11: Mercury (II) binding activity of selected vegetable and fruit juices. All tested at $1 \mathrm{mg} \mathrm{Hg}(\mathrm{II}) / \mathrm{mL}$.

Methionine, cysteine, and selenium content in relation

\section{to mercury (ii) binding activity}

It has been well established that interactions between mercury and dietary selenium, zinc, thiols, and fiber exist and play a role in the ultimate toxicity of mercury in the human body [37]. However, further research is needed to clarify all aspects related to the absorption, distribution, metabolism, excretion and possible re-distribution of mercury in the presence of nutritional and bioactive compounds. Data on the content of methionine, cysteine and selenium in whole fruits and vegetables used in the analyses here were pooled from the "nutritiondata.self.com" website (Table 1) and then plotted against the $\mathrm{Hg}$ (II) binding activity of 10, 25 and $50 \%$ juices. Alanine was used as a negative control, since it has not been implicated in mercury interactions. It was assumed that juices contain proportional amounts of minerals and amino acids to whole foods. However, no correlation between methionine, cysteine and selenium content or volume of juice obtained per gram of plant material and activity was found. (Figure 12) illustrates the percentages of $\mathrm{Hg}$ (II) binding activity in relation to methionine content at $10 \%$ juice concentration, showing thatgarlic, broccoli and kale had the highest, with $62.2 \%, 32.3 \%$ and $30.2 \%$, respectively. The methionine content of these vegetables was also high, with values of 76, 38 and $32 \mathrm{mg} / 100 \mathrm{~g}$, respectively (Table 1). In comparison, Brazil nut milk, almond nut milk and cow milk had higher methionine content, with values of 1008, 151 and $83 \mathrm{mg} / 100 \mathrm{~g}$, respectively (Table 1 ). The same table also shows that, in comparison with all vegetables except garlic, brazil nut, almond nut and cow milk also had higher cysteine and selenium content.

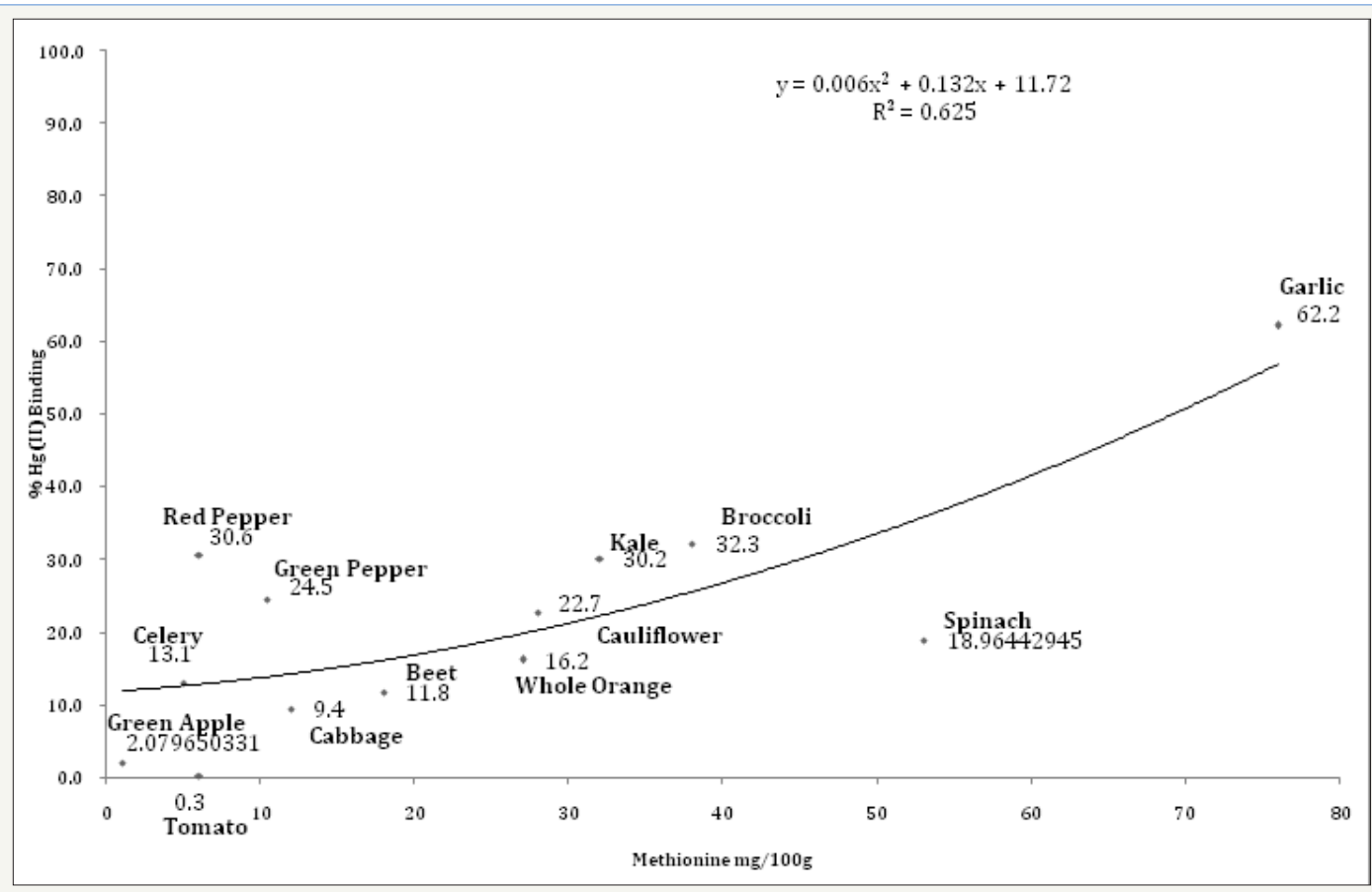

Figures 12: The mercury (II) binding activity of selected juices (at 10\% strength) versus methionine content. 


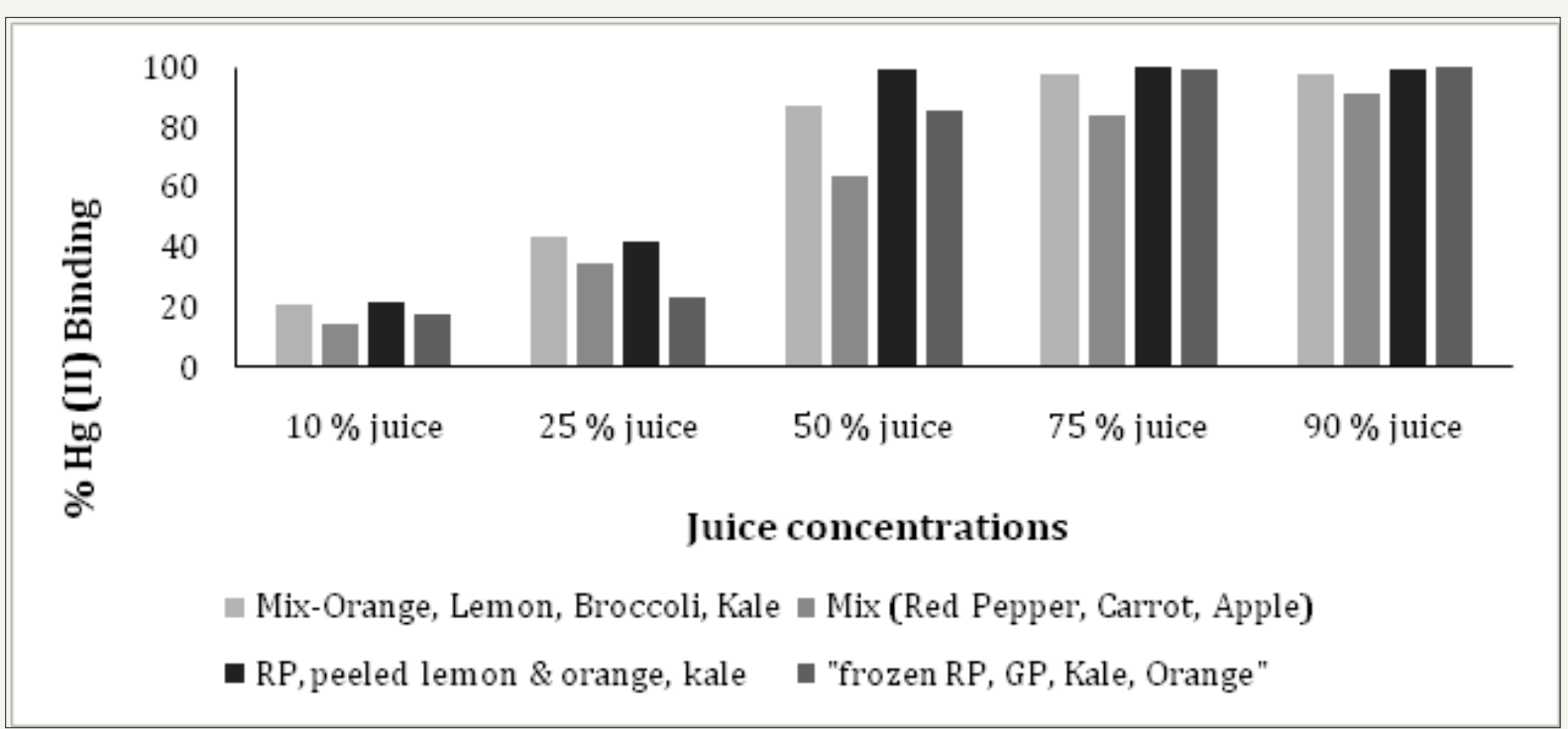

Figures 13: The mercury (II) binding activity of different concentrations of mixed juices.

Irregardless of methionine, selenium and cysteine content, (Figure 10) shows the $\mathrm{Hg}$ (II) binding activity of Brazil, almond and cow milk using a mercury concentration of $1 \mathrm{mg} \mathrm{Hg}(\mathrm{II}) / \mathrm{ml}$. At $50 \%$ milk concentration, Brazil nut, almond nut and cow milk had $\mathrm{Hg}$ (II) binding activity of $84.2,78.2$ and $52.7 \%$, respectively. However, at the same 50\% concentration (Figure 11 and Table 2) shows that red pepper, kale, broccoli, garlic, green pepper and cauliflower had higher Hg (II) binding activity, with percentages of 99.8, 98.8, 98.7, 93.5, 91.7 and 90.2\%, respectively. When different juice combinations were tested to determine variations in $\% \mathrm{Hg}$ (II) binding activity, at $50 \%$ concentration it was found that the kale, red pepper, peeled lemon and orange mix showed the highest potential, with a value of $99.4 \%$, followed by the juice combination of kale, broccoli, orange and lemon at $87.6 \%$ of $\mathrm{Hg}$ (II) binding activity (Figure 13). These findings suggest that other phytochemicals in vegetable and fruit juices, like chlorophyll, antioxidants, and pectins also appear to be responsible for the activity, which is consistent with the literature [37-39].

\section{Conclusion}

The current study demonstrated that select vegetables tested at different juice concentrations (10\%, 25\%, 50\%, 75\%, and 100\%) showed good potential for Hg (II) binding activity, which could be applied as a chelation technique to individuals contaminated with mercury. The vegetables with the highest $\mathrm{Hg}$ (II) binding activity were from Brassicaceae (kale, broccoli, cauliflower and cabbage), Amaryllidaceae (garlic), Capsicum (red and green peppers) and Amaranthaceae (spinach). The most promising vegetable was red pepper, which at $50 \%$ concentration bound $99.8 \%$ of the mercury (II), probably due to its high antioxidant content. Other top binding vegetables were kale (98.8\%), green pepper (98.8\%), and broccoli (98.7\%). It appears that the high mercury II binding potential of these vegetables may be related to their high methionine content, which is an important sulphur-containing proteinogenic amino acid. When vegetable juices were mixed with different fruits to make them more palatable, the following combinations were the most effective at binding mercury (II) at $50 \%$ concentration

a) Red pepper, lemon, orange, and kale (99.4\%)

b) Kale, orange, lemon, and broccoli (87.7\%)

Further studies both in vitro and in vivo are needed to prove the effectiveness of vegetable and fruit juices for the removal of heavy metals from humans and animals. Considering that methyl mercury ( $\mathrm{MeHg}$ ) is the pathway for mercury contamination through food, analysis of MeHg bio accessibility from a fish matrix in the laboratory using in vitro digestion has been initiated to further analyze mercury interactions with different fruit and vegetable juices. The results of these further steps will help to elucidate what treatment programs could be applied to detoxify individuals contaminated with mercury, both from inhalation of mercury vapour and also from ingestion of methyl mercury via food sources. In order to improve the health of artisanal miners and their families, in areas of dense gold processing using mercury like in Portovelo, Ecuador, this kind of initiative is urgently needed.

In order to effectively introduce a juice program incorporating the use of selected vegetables with high mercury-binding capacity and available locally, it is imperative to first consult with locals regarding their interest in participating in a second step of this study. To begin with, an assessment of all contaminated individuals in the area, including miners and other family members, needs to be conducted.

\section{References}

1. López V, Patricio C, Veiga, Marcello M, Hall K (2010) Mercury balance in amalgamation in artisanal and small-scale mining: findings ways to reduce environmental pollution in portovelo-zaruma, ecuador. Journal of Cleaner Production 18(3): 226-232.

2. Cordy P, Veiga MM, Salih I, Al Saadi S, Console S, et al. (2011) Mercury contamination from artisanal gold mining in antioquia, colombia: the world's highest per capita mercury pollution. Sci Total Environ 410-411: 154-160. 
3. Research Triangle Institute (1999) Agency for toxic substances and disease registry. Toxicological profile for mercury. Atlanta: US Department of Health and Human Services.

4. Sears ME (2013) Chelation: harnessing and enhancing heavy metal detoxification-a review. Scientific World Journal, pp. 1-13.

5. Rowland IR, Mallett AK, Flynn J, Hargreaves RJ (1986) The effect of various dietary fibres on tissue concentration and chemical form of mercury after methylmercury exposure in mice. Arch Toxicol 59(2): 94 98.

6. Lapina VA, Sheshko PM, Pankovets EA, Dontsov AE (2000) Phytosorbent prepared from sunflower seed husks prevents mercuric chloride accumulation in kidney and muscle of adult rabbits. Arch Environ Health 55(1): 48-50

7. Orct T, Lazarus M, Jurasović J, Blanusa M, Piasek M, et al. (2009) Influence of selenium dose on mercury distribution and retention in suckling rats. J ApplToxicol 29(7): 585-589.

8. Martin MD, Naleway C (2004) The inhibition of mercury absorption by dietary ethanol in humans: cross-sectional and case-control studies. Occup Environ Med 61(2): e8.

9. Li YF, Dong Z, Chen C, Li B, Gao Y, et al. (2012) Organic selenium supplementation increases mercury excretion and decreases oxidative damage in long-term mercury-exposed residents from wanshan, China. Environ Sci Technol 46(20): 11313-11318.

10. Eliaz I, Weil E, Wilk B (2007) Integrative medicine and the role of modified citrus pectin/alginates in heavy metal chelation and detoxification - five case reports. Forsch Komplementmed 14(6): 358-364.

11. Eliaz I, Hotchkiss AT, Fishman ML, Rode D (2006) The effect of modified citrus pectin on urinary excretion of toxic elements. Phytother Res 20(10): 859-864

12. Zhao ZY, Liang L, Fan X, Yu Z, Hotchkiss AT (2008) The role of modified citrus pectin as an effective chelator of lead in children hospitalized with toxic lead levels. Altern Ther Health Med 14(4): 34-38.

13. Nuttall KL (2004) Interpreting mercury in blood and urine of individual patients. Ann Clin Lab Sci 34(3): 235-250.

14. Ojo JO, Oketayo O, Adesanmi CA, Horvat M, Mazej D, et al. (2014) Influence of nutritional status on some toxic and essential elements in the blood of women exposed to vehicular pollution in Ile-Ife, Nigeria. Environ Sci Pollut Res Int 21(2): 1124-1132.

15. Oomen AG, Rompelberg CJ, Bruil MA, Dobbe CJ, Pereboom, et al. (2003) Development of an in vitro digestion model for estimating the bio accessibility of soil contaminants. Arch Environ Contam Toxicol 44(3): 281-287.

16. Versantvoort $\mathrm{CH}$, Oomen AG, VandeKamp E, Rompelberg, Sips AJ (2005) Applicability of an in vitro digestion model in assessing the bioaccessibility of mycotoxins from food. Food and Chemical Toxicology 43(1): 31-40.

17. Cabañero AI, Madrid Y, Cámara C (2007) Mercury-selenium species ratio in representative fish samples and their bioaccessibility by an in vitro digestion method. Biol Trace Elem Res 119(3): 195-211.

18. Shim SM, Lasrado JA, Dorworth LE, Santerre CR (2005) Mercury and omega-3 fatty acids in retail fish sandwiches. J Food Prot 68(3): 633-635.

19. Spiegel S, Veiga, M (2010) International guidelines on mercury management in small-scale gold mining. Journal of Cleaner Production 18(4): 375-385.

20. Veiga MM, Baker R (2004) Protocols for environmental and health assessment of mercury released by artisanal and small-scale gold miners. Vienna, p. 289
21. Hacon (1990) Mercury contamination in Brazil. Technical Report, FINEP Studies and Projects Financier, Rio De Janeiro, Brazil, p. 85.

22. WHO (1991) World Health Organization. Environmental health criteria 118: Inorganic mercury. Geneva, Switzerland, p. 168.

23. Suzuki T (1979) Dose-effect and dose-response relationships of mercury and its derivatives. In: Nriagu JO (Ed.), The Biogeochemistry of Mercury in the Environment Elsevier/North- Holland Biomedical Press, Amsterdam, Netherlands, pp. 299-431.

24. Jang MY, Yum YT (1989) An intervention study on the outbreak of occupational mercury poisoning. Korea University Medical Journal 26: 67-77.

25. Wee KS, Choi TS, Lee SJ, Cho WY, Kim HK, et al. (1990) A clinical study of chronic mercury poisoning. The Korean Journal of Internal Medicine 38: 51-57.

26. WHO (2000) World Health Organization. In: (Chapter 6.9) Mercury, Air Quality Guidelines. WHO Regional Office for Europe, Copenhagen, Denmark.

27. Stopford W (1979) Industrial exposure to mercury. In: Nriagu JO (Ed.) The Biogeochemistry of Mercury in the Environment. Elsevier/NorthHolland Biomedical Press, Amsterdam, Netherlands, pp. 367-397.

28. Jones HR (1971) Mercury Pollution Control, Noyes Data, New Jersey, USA, p. 251

29. Bermudez V, Ferreira P, Gunson P (2004) United Nations Development Organization. Mercury pollution from artisanal gold mining in Block B, El Callao, Bolivar State, Venezuela: Health and Technological Vienna, Austria, p. 55

30. UNIDO (2016) Implementing integrated measures for minimizing mercury releases from artisanal gold mining in ecuador.

31. Carrasco G, Velásquez L, Olivero Verbel J, Pájaro Castro N (2011) Air mercury contamination in the gold mining town of portovelo, ecuador Bull Environ Contam Toxicol 87(3): 250-253.

32. Instituto Nacional de Salud (2015) Epidemiological surveillance and health impact assessment due to occupational and environmental exposure to mercury in the region of La Mojana, Directorate of Surveillance and Risk Analysis in Public Health. Directorate of Public Health Research, Colombia, USA.

33. WHO (2007) World Health Organization. Exposure to mercury. Public Health and Environment Geneva, Switzerland.

34. Mahaffey KR (2005) Mercury exposure: medical and public health issues. Trans Am Clin Climatol Assoc 116: 127-154.

35. Mason HJ, Hindell P, Williams NR (2001) Biological monitoring and exposure to mercury. Occup Med 51(1): 2-11.

36. Ahmed MJ, Alam MS (2003) A rapid spectrophotometric method for the determination of mercury in environmental, biological, soil and plant samples using diphenylthiocarbazone. Spectroscopy 17(1): 45-52.

37. Rooney J (2007) The role of thiols, dithiols, nutritional factors and interacting ligands in the toxicology of mercury. Toxicology 234(3): 145156.

38. Sears ME (2013) Chelation: harnessing and enhancing heavy metal detoxification -a review. Scientific World Journal, pp. 1-13.

39. Flora SJ, Pachauri V (2010) Chelation in metal intoxication. Int J Environ Res Public Health 7(7): 2745-88. 
Creative Commons Attribution 4.0 International License

For possible submissions Click Here

Submit Article

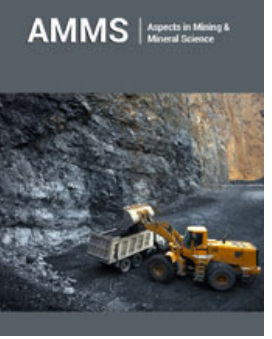

\section{Aspects in Mining \& Mineral Science}

\section{Benefits of Publishing with us}

- High-level peer review and editorial services

- Freely accessible online immediately upon publication

- Authors retain the copyright to their work

- Licensing it under a Creative Commons license

- Visibility through different online platforms 